\title{
Pengembangan Bahan Ajar Berbasis Multimedia Materi Pengetahuan Dasar Pemetaan Pada Mata Pelajaran Geografi Kelas X Kurikulum 2013 di SMA Muhammadiyah Wonosari
}

\author{
Developing Multimedia Based Teaching Materials of Basic Mapping Knowledge on Geography \\ Subject Class X Curriculum 2013 in SMA Muhammadiyah Wonosari \\ Moh Iwan Darmawan ${ }^{1}$,Muhammad Sholeh ${ }^{2}$ \\ ${ }^{1}$ SMA Muhammadiyah Wonosari Gunung Kidul \\ J1 KH. Agus Slaim Gg Bougenvile, Kel. Kepek, Kec. Wonosari, Gunungkidul, DIY \\ Email : iwangeo.tik@gmail.com \\ ${ }^{2}$ Teknik Informatika- Institut Sains \& Teknologi AKPRIND Yogyakarta, \\ J1. Kalisahak 28 Kompleks Balapan Yogyakarta \\ Email:muhash@akprind.ac.id
}

\begin{abstract}
ABSTRAK
Di era perkembangan teknologi informasi (TIK) yang sangat pesat, proses belajar mengajar di sekolah tidak hanya bisa mengandalkan proses pembelajaran di kelas. Dengan menggunakan TIK baik guru maupun siswa dapat melakukan pembelajaran lebih interaktif dan dapat dilengkapi dengan fasilitas multimedia. Dengan mengembangkan bahan ajar berbasis TIK, materi pembelajaran yang disampaikan dapat dilengkapi dengan suara, animasi dan contoh- contoh materi dalam bentuk simulasi.

Pengembangan materi Pengetahuan Dasar Pemetaan dalam indikator Pencapaian Kompetensi Pengindraan Jauh pada mata pelajaran geografi Kelas X IPS Kurikulum 2013 dengan memanfaatkan TIK dapat disajikan lebih interaktif dan menarik serta dapat disajikan dalam bentuk animasi. Bahan ajar yang dikembangkan dibuat dengan menggunakan aplikasi video scribe. Penggunaan aplikasi ini, dalam pembuatan bahan ajar dapat dilakukan dengan mudah dan menghasilkan tampilan bahan ajar yang lebih interaktif dan siswa lebih tertarik untuk melihat dan mempelajari materi yang dibuat dengan memanfaatkan TIK.
\end{abstract}

Kata kunci : Bahan ajar, multimedia, geografi, guru

\begin{abstract}
In the era of rapid development of information and communication technology (ICT), the process of teaching and learning in schools can not only rely on the process of learning in the classroom. By using ICT both teachers and students can do more interactive learning and can be equipped with multimedia facilities. By developing ICT-based teaching materials, learning materials delivered can be complemented by sound, animation and material examples in the form of simulations. The development of Basic Knowledge Mapping Material in indicators of Achievement of Remote Sensing Competence on geography subjects Class X IPS Curriculum 2013 by utilizing ICT can be presented more interactive and interesting and can be presented in the form of animation. The developed teaching material is created using the video scribe application. The use of this application can be done easily and produce a more interactive teaching materials. Therefore, the students are more interested to see and learn materials created using ICT.
\end{abstract}

Keywords: teaching materials, multimedia, geography, teachers

\section{PENDAHULUAN}

Perkembangan teknologi informasi saat ini mampu meningkatkan kinerja dan memungkinkan berbagai kegiatan dapat dilaksanakan dengan lebih cepat dan akurat. Komputer merupakan salah satu perangkat teknologi yang dapat membantu menyelesaikan persoalan dan dapat membantu dalam proses promosi produk secara efektif. Dengan pesat nya perkembangan teknologi informasi mendorong munculnya aplikasi multimedia yang dinamis. Multimedia merupakan alat atau 
sarana yang merepresentasikan informasi dengan menggunakan kombinasi dari teks, suara, gambar, animasi, dan video. Dengan kelebihan nya itu, multimedia dapat dikatakan sebagai salah satu cara yang tepat untuk mempermudah penyampaian suatu informasi kepada masyarakat. Dengan adanya multimedia, baik secara langsung maupun tidak langsung telah mengubah cara manusia berinteraksi dengan komputer.

Bidang pendidikan merupakan salah satu bidang yang telah menggunakan atau memanfaatkan kemajuan teknologi komputer. Teknologi komputer dapat memberikan kemudahan dalam pengembangan bahan ajar yang akan digunakan siswa. Dengan bantuan komputer bahan ajar dapat dibuat lebih interaktif dan dilengkapi dengan animasi. Melihat hal tersebut maka muncul pemikiran untuk menerapkan konsep multimedia dalam pengembangan materi bahan ajar mata pelajaran geografi khususnya materi Pengetahuan Dasar Pemetaan pada Kelas X IPS K13. Modul geografi Pengindraan Jauh (Darmawan, 2017). Materi Pengetahuan Dasar pemetaan, yang diberikan pada semester Ganjil kelas X IPS merupakan materi yang mengupas mengenai dasar, komponen, Pengindraan Jauh dan Analisis Citra Satelit dengan menggunakan multimedia tentunya proses pembelajaran yang diberikan ke siswa dapat lebih interaktif sehingga siswa dapat lebih memahami materi dibanding mempelajari materi dengan menggunakan buku saja. Hasil pengembangan aplikasi ini memberikan gambaran produk bahan ajar yang menjelaskan materi dengan dilengkapi dengan gambar dan animasi dengan harapan dapat mempermudah dalam proses pembelajaran yang dilakukan siswa

\section{TINJAUAN PUSTAKA}

Salah satu materi dalam pelajaran Geografi yang membutuhkan banyak penjelasan dan media pendukung dalam penyampaiannya adalah Sparkol VideoScribe materi Pengetahuan Dasar Pemetaan merupakan materi pelajaran kelas $X$ semester 1 pada Kurikulum 2013 dan materi ini mengkaji dasar pemetaan, pengindraan jauh, dan sistem informasi geografis khususnya konsep-konsep Komponen Pengindraan Jauh dan Analisis Citra Satelit.
Agar proses pengembangan bahan ajar dapat lebih dipahami, pengemabnagan bahan ajar dikembangkan dengan mengoptimalkan dukungan multimedia. Istilah multimedia yang digunakan dalam pembahasan ini adalah sebuah program untuk penyampaian konten digital secara keseluruhan dengan menggunakan kombinasi terpadu antara teks, audio, gambar dua dimensi (2D) dan tiga dimensi (3D), video dan animasi. Dalam bentuk yang paling sederhana, multimedia kadangkadang didefinisikan sebagai presentasi konten yang menggunakan kombinasi media [teks, suara, gambar (statis, bergerak, animasi, video)]. Secara umum konsep multimedia dapat didefinisikan gabungan dari berbagai media teks, gambar, video dan animasi dalam satu program berbasis komputer yang dapat memfasilitasi komunikasi interaktif. (Munir, 2013). Gambar 1, menggambarkan piranti multimedia dalam suatu aplikasi

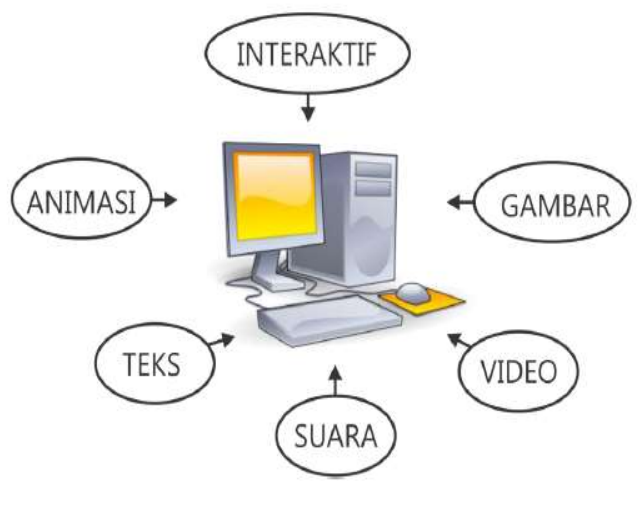

Gambar 1 Konsep Multimedia

Dengan adanya multimedia ini, bahan ajar yang dikembangkan disajikan dalam bentuk yang sederhana dan mudah dimengerti baik dalam bentuk teks, animasi, video maupun gambar. Penyajian materi disertai audio, animasi, gambar maupun video akan mempermudah siswa dalam memahami nya.

Banyak peneliti yang sudah mengembangkan bahan ajar yang menggunakan komputer dan multimedia, beberapa hasil penelusuran pustaka yang berupa penelitian yang menggunakan multimedia diantaranya :

Dianingrum (2012), mengembangkan pembelajaran untuk mempelajari huruf Hiragana. Dalam mempelajari huruf Hiragana siswa sering mengalami kesulitan diantaranya penulisan huruf-huruf yang memerlukan daya 
ingat yang cukup tinggi, karena dalam menuliskan huruf-huruf nya terdapat beberapa langkah. Jika satu langkah saja lupa atau tertukar, huruf yang dihasilkan akan salah, selain itu kurangnya media pengajaran yang digunakan oleh guru karena guru menyampaikan materi hanya menggunakan buku panduan dengan menggunakan sistem ceramah. Hal itu membuat siswa enggan untuk mempelajari

Ria Putri Wahyuningtyas (2013), pada penelitian menghasilkan sebuah multimedia pembelajaran yang dikemas dalam bentuk $C D$ serta dilengkapi dengan buku petunjuk penggunaan media. Multimedia pembelajaran disajikan dalam dua bahasa yaitu bahasa Indonesia dan bahasa Inggris. Multimedia pembelajaran ini bisa digunakan oleh guru maupun siswa. Guru dapat menggunakan multimedia pembelajaran ini untuk mempermudah penyampaian materi koloid di kelas sedangkan siswa dapat menggunakan multimedia pembelajaran ini secara mandiri sebagai penunjang belajar dengan tujuan agar siswa mampu memahami materi sistem koloid dengan lebih baik.

Rohmani (2015), dalam penelitian mengembangkan media pembelajaran fisika berbasis multimedia interaktif terintegrasi dengan lembar kerja siswa dan dikembangkan dengan menggunakan Software Adobe Flash dan XML dengan hasil produk dikemas dalam keping CD yang didalamnya berisi software utama media dan beberapa file pendukung dari media tersebut. Media disajikan dengan dua pembagian materi yaitu materi pembelajaran dan materi penjelasan yang diproteksi serta berisi bank soal yang dapat diupdate.

Lusiana (2017), dalam makalahnya pengembangan LKS tematik berbasis komik yang dikembangkan di MTs Bustanul Ulum merupakan salah satu jenis inovasi perangkat pembelajaran yang disajikan dalam LKS untuk siswa. Komponen LKS yang dikembangkan meliputi halaman muka (cover), pengenalan tokoh, indikator, pendahuluan, bekal awal, tujuan kegiatan, alat dan bahan, petunjuk kegiatan, gambar kerja, tabel pengamatan, pertanyaan, dan kesimpulan. LKS yang dikembangkan dapat menarik perhatian siswa karena menggunakan LKS berbentuk komik, penyajiannya yang mengandung unsur visual, cerita kuat dan dapat mengoptimalkan peran LKS.

\section{METODOLOGI PENELITIAN}

Sebelum melakukan pengembangan bahan ajar, langkah dalam penelitian adalah melakukan analisis sistem terhadap materi yang akan dikembangkan dan melakukan perancangan serta implementasi sistem.

\section{Analisis sistem}

Analisis sistem dilakukan dengan melihat isi materi yang akan dikembangkan. Adapun materi yang dikembangkan diantaranya (Waluyo, 2009)

Materi yang dibahas Pengetahuan Dasar Pemetaan. Kompetensi Dasar yang ingin dicapai memahami dasar- dasar pemetaan, Pengindraan Jauh, dan Sistem Informasi Geografis (SIG) dan indikator: siswa dapat memahami indikator pencapaian kompetensi dasar-dasar pemetaan, pengindraan jauh, dan sistem informasi geografis dan jenis citra Pengindraan Jauh dan interpretasi citra.

\section{Perancangan sistem}

Perangkat keras dan perangkat lunak yang akan dikembangkan adalah: Perangkat keras yang digunakan diantaranya Processor 1.6 GHz dan RAM $1 \mathrm{~GB}$

Perangkat lunak yang digunakan dalam pembuatan multimedia pembelajaran ini diantaranya Microsoft Windows 7 Ultimate dan Sparkol Video Scribe

\section{Sparkol Video Scribe}

Sparkol Videoscribe adalah aplikasi yang digunakan untuk membuat sebuah video dengan animasi tulis tangan. Di dalam aplikasi ini terdapat banyak animasi keren dan unik, sehingga akan membuat peserta didik lebih suka dan terhibur dalam kegiatan belajar mengajar. Namun tidak hanya itu, software ini juga dapat digunakan sebagai sarana promosi, presentasi, bisnis online dan kegiatan lainnya. Dengan adanya software ini, dalam pengembangan bahan ajar dapat dikembangkan dengan mudah dalam menyampaikan materi, karena proses penyajian materi dengan animasi dapat dilakukan dengan sederhana dan mudah. (Air, 2015)

\section{Pembuatan Desain Media}

Dalam tahap ini dilakukan penentuan konsep dari multimedia pembelajaran. Media ini didesain sebagai alat bantu pembelajaran 
baik bagi guru maupun siswa. Hasil dari tahap ini adalah desain media berupa skema dan juga storyboard. Storyboard tersebut berisi gambaran kasar dari multimedia.

\section{Rancangan Storyboard Menu Utama}

Rancangan storyboard menu utama merupakan rancangan halaman yang bisa diakses setelah halaman pembuka, adapun rancangan nya seperti pada gambar 2 dan gambar 3 merupakan storyboard dari salah satu materi yang akan dikembangkan

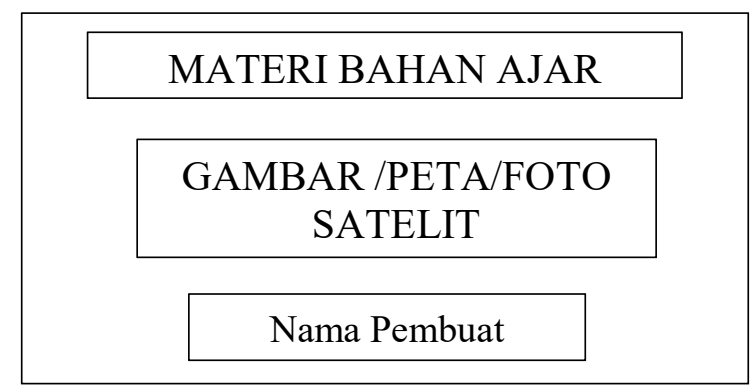

Gambar 2 Rancangan storyboard menu utama

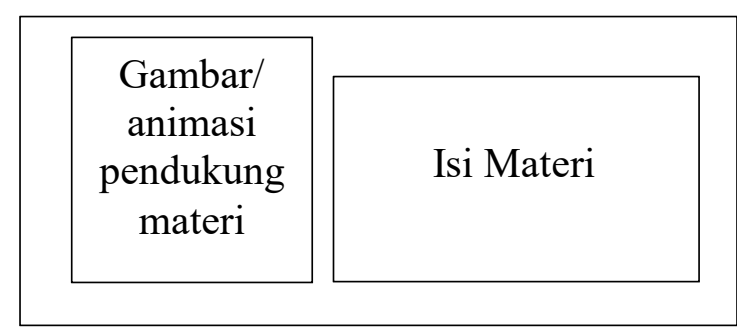

Gambar 3 Storyboard Materi

\section{Rancangan di Video Scribe}

Tahapan selanjutnya adalah memindahkan hasil rancangan dalam story board ke aplikasi video scribe. Gambar 4 merupakan contoh rancangan dalam video scribe.

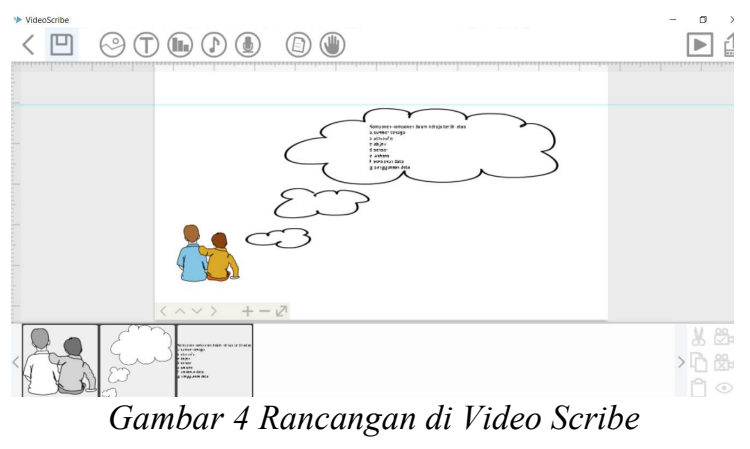

Dalam rancangan di video scribe, diatur beberapa pengaturan, seperti waktu (dalam detik) yang digunakan untuk menggambar gerakan proses animasi, gerakan tangan atau animasi yang digunakan untuk menulis suatu teks serta pengaturan lainnya seperti ukuran huruf, jenis huruf dan pengaturan lainnya. Gambar 5 salah satu proses pengaturan untuk menentukan animasi yang digunakan untuk menulis teks

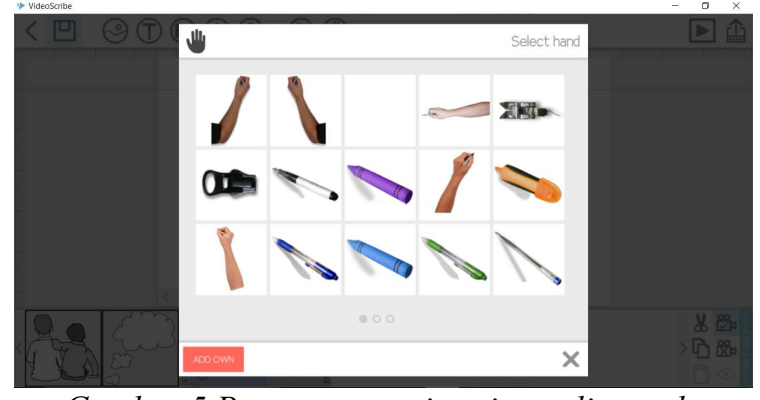

Gambar 5 Pengaturan animasi penulisan teks

Hasil rancangan di atas dapat dilihat hasilnya dalam bentuk preview. Gambar 6 merupakan contoh hasil dari rancangan video scribe.

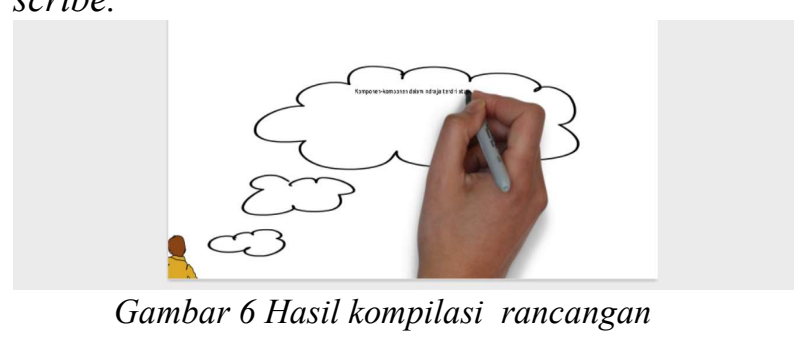

\section{PEMBAHASAN}

Hasil

Pada tahap implementasi hasil rancangan aplikasi, aplikasi dirancang agar dapat dioperasikan dalam kondisi sebenarnya, sehingga langkah ini dapat dipastikan bahwa aplikasi tersebut dapat menghasilkan tujuan yang diinginkan dengan lebih efisien atau aplikasi tersebut masih harus diperbaiki. Hasil dari aplikasi ini adalah sebuah tampilan program dengan beberapa halaman aplikasi yang interaktif. Tujuannya adalah : menerapkan aplikasi yang telah dirancang untuk diterapkan pada keadaan sebenarnya dan dievaluasi apakah menghasilkan aplikasi yang baik atau sebaliknya. Dikatakan akan menghasilkan aplikasi yang baik jika aplikasi yang digunakan dapat mencapai tujuan dengan prinsip efisien dan efektif. Dikatakan aplikasi tidak berhasil jika aplikasi tersebut, ternyata banyak kelemahan dan kekurangan sehingga tidak efisien. 


\section{Pembahasan}

Tampilan awal dari bahan ajar multimedia ini menampilkan identitas materi yang dibahas serta identitas penulis. Gambar 7 merupakan tampilan halaman pembuka video. Bahan ajar berbasis multimedia yang dikembangkan sudah dilengkapi dengan unsurunsur multimedia. Aplikasi dilengkapi dengan animasi yang bergerak yang menggambarkan proses penjelasan materi serta suara, gambar dan video

Halaman depan ini menginformasikan materi yang akan dibahas dan kompetensi yang dasar dari materi yang dibuat bahan ajar berbasis multimedia ini

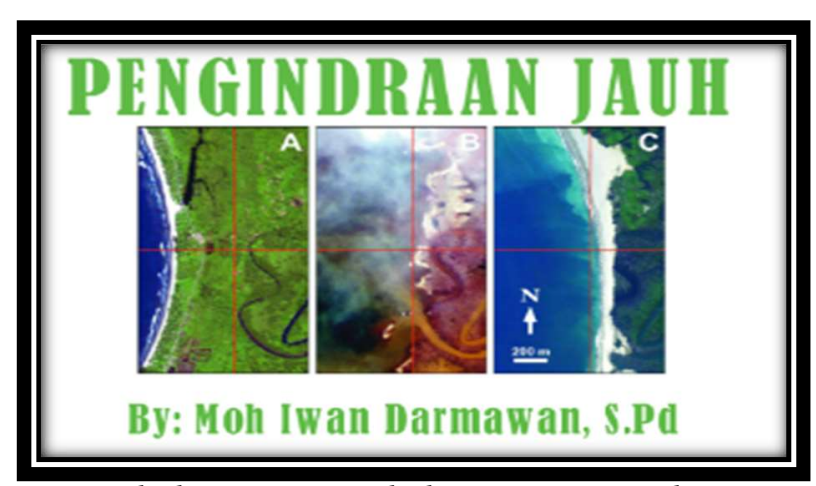

Dari halaman pembuka, siswa dapat melanjutkan pembelajaran materi yang terkait dengan penginderaan jauh seperti komponen penginderaan jarak jauh, Interaksi Antara Tenaga dan Objek, Citra, Interpretasi citra. Gambar 8 dan 9 merupakan hasil dari bahan ajar lainnya.

\section{KESIMPULAN}

Dengan adanya bahan ajar ini, memberikan alternatif lain bagi siswa untuk mendapatkan materi pembelajaran. Dengan menggunakan multimedia, suatu bahan ajar dapat memberikan pemahaman yang lebih cepat terhadap siswa dikarenakan cara penyampaiannya yang ringkas dan sederhana. Dengan menggunakan aplikasi tertentu proses pembuatan bahan ajar tidak lagi menjadi sesuatu yang sulit. Dengan aplikasi yang dikhususkan untuk membuat bahan ajar, pembuatan bahan ajar dapat dilakukan dengan mudah dan hasil dari bahan ajar dapat ditampilkan demgan lebih baik dan menarik.

\section{UCAPAN TERIMA KASIH}

Ucapan terima kasih kami sampaikan kepada tim Ipteks bagi Masyarakat (IbM) IST AKPRIND Yogyakarta yang telah memberikan pelatihan pembuatan bahan ajar dan penulisan karya ilmiah di SMA Muhammadiyah.

\section{DAFTAR PUSTAKA}

Air, J., Oakland, E., \& Walters, C. (2015). THE Secrets Behind The Rise Of Video Scribing. Bristol, UK: Sparkol Books.

Darmawan, M. I. (2017). Modul Penginderaan Jarak Jauh. Gunung Kidul: SMA Muhammadiyah Wonosari.

Dianingrum, M., \& Maskur. (2012). Multimedia Pembelajaran Huruf Hiragana Kelas X di SMA Negeri 1 PURWAREJA KLAMPOK. Jurnal Telematika, 5(1), 81-88.

Lusiana, Z., Wahyuni, S., \& Putra, P. D. (2017). Pengembangan LKS Tematik Berbasis Komik Pada Mata Pelajaran IPA di SMP. JURNAL PEMBELAJARAN FISIKA, 6(3), 239246.

Munir. (2013). MULTIMEDIA Konsep \& Aplikasi dalam Pendidikan. Bandung: Penerbit Alfabeta.

Rohmani, Sunarno, W., \& Sukarmin). (2015). Pengembangan Media Pembelajaran Fisika Berbasis Multimedia Interaktif Terintegrasi Dengan LKS Pokok Bahasan Hukum Newton Tentang Gerak Kelas X SMA/MA. JURNAL INKUIRI, 4(1), 152-162.

Wahyuningtyas, R. P., Munzil, \& Suharti. (2013). Pengembangan Multimedia Pembelajaran Kimia Kelas XI SMA Pada Materi Koloid. Jurnal Pendidikan Kimia Universitas Negeri Malang, 2(2), $1-9$.

Waluyo, B. (2009). Memahami Geografi SMA. Jakarta: Penerbit ARMICO. 
21 Jurnal Multimedia \& Artificial Intelligence, Volume 1, Nomor 1, Februari 2017

Fakultas Teknologi Informasi, Universitas Mercu Buana Yogyakarta 